Virginia Commonwealth University

vCU Scholars Compass

Neurology Publications

Dept. of Neurology

2014

\title{
Development of status epilepticus, sustained calcium elevations and neuronal injury in a rat survival model of lethal paraoxon intoxication
}

Laxmikant Sudhir Deshpande

Virginia Commonwealth University, laxmikant.deshpande@vcuhealth.org

Dawn S. Carter

Virginia Commonwealth University

Kristin Phillips

Virginia Commonwealth University, fentonkl@vcu.edu

Robert E. Blair

Virginia Commonwealth University, rblair@vcu.edu

Polpewt thisednodeagititional works at: http://scholarscompass.vcu.edu/neurology_pubs

r. rinia Commonwealth University, rdeloren@vcu.edu

Part of the Neurology Commons

(C) 2014 Elsevier Inc. All rights reserved. NOTICE: this is the author's version of a work that was accepted for publication in NeuroToxicology. Changes resulting from the publishing process, such as peer review, editing, corrections, structural formatting, and other quality control mechanisms may not be reflected in this document. Changes may have been made to this work since it was submitted for publication. A definitive version was subsequently published in NeuroToxicology Volume 44, September 2014, Pages 17-26, doi:10.1016/j.neuro.2014.04.006.

\section{Downloaded from}

http://scholarscompass.vcu.edu/neurology_pubs/9

This Article is brought to you for free and open access by the Dept. of Neurology at VCU Scholars Compass. It has been accepted for inclusion in Neurology Publications by an authorized administrator of VCU Scholars Compass. For more information, please contact libcompass@vcu.edu. 


\section{Development of status epilepticus, sustained calcium elevations and neuronal injury in a rat survival model of lethal paraoxon intoxication}

Laxmikant S. Deshpande*, Dawn S. Carter*, Kristin F. Phillips*, Robert E. Blair* and Robert J. DeLorenzo ${ }^{1} * *$

Departments of Neurology*, Pharmacology and Toxicology ${ }^{\dagger}$, and Molecular Biophysics and Biochemistry . Virginia Commonwealth University, Richmond, Virginia 23298, USA

To whom correspondence should be addressed:

${ }^{1}$ Robert J. DeLorenzo, M.D., Ph.D., M.P.H.

Virginia Commonwealth University

School of Medicine

PO Box 980599

Richmond, VA 23298

Phone: 804-828-3392

Fax: 804-828-6432

E-mail: rdeloren@hsc.vcu.edu 


\begin{abstract}
Paraoxon (POX) is an active metabolite of organophosphate $(\mathrm{OP})$ pesticide parathion that has been weaponized and used against civilian populations. Exposure to POX produces high mortality. OP poisoning is often associated with chronic neurological disorders. In this study, we optimize a rat survival model of lethal POX exposures in order to mimic both acute and longterm effects of POX intoxication. Male Sprague-Dawley rats injected with POX (4 mg/kg, icecold PBS, s.c.) produced a rapid cholinergic crisis that evolved into status epilepticus (SE) and death within 6-8 min. The EEG profile for POX induced SE was characterized and showed clinical and electrographic seizures with $7-10 \mathrm{~Hz}$ spike activity. Treatment of $100 \%$ lethal POX intoxication with an optimized three drug regimen (atropine, $2 \mathrm{mg} / \mathrm{kg}$, i.p., 2-PAM, $25 \mathrm{mg} / \mathrm{kg}$, i.m. and diazepam, $5 \mathrm{mg} / \mathrm{kg}$, i.p.) promptly stopped $\mathrm{SE}$ and reduced acute mortality to $12 \%$ and chronic mortality to $18 \%$. This model is ideally suited to test effective countermeasures against lethal POX exposure. Animals that survived the POX SE manifested prolonged elevations in hippocampal $\left[\mathrm{Ca}^{2+}\right]_{\mathrm{i}}\left(\mathrm{Ca}^{2+}\right.$ plateau $)$ and significant multifocal neuronal injury. POX SE induced $\mathrm{Ca}^{2+}$ plateau had its origin in $\mathrm{Ca}^{2+}$ release from intracellular $\mathrm{Ca}^{2+}$ stores since inhibition of ryanodine/ $\mathrm{IP}_{3}$ receptor lowered elevated $\mathrm{Ca}^{2+}$ levels post $\mathrm{SE}$. POX SE induced neuronal injury and alterations in $\mathrm{Ca}^{2+}$ dynamics may underlie some of the long term morbidity associated with OP toxicity.
\end{abstract}

Keywords: paraoxon, status epilepticus, survival model, $\mathrm{Ca}^{2+}$ dynamics, Sprague-Dawley rats 


\section{Introduction}

Paraoxon (POX) is an active metabolite of organophosphate (OP) insecticide parathion that has been weaponized and has caused human casualties (Federation of American Scientists, 1998; Gould and Folb, 2003; Croddy et al., 2004; Moorcraft and McLaughlin, 2008). POX is a potent acetylcholinesterase $(\mathrm{AChE})$ inhibitor that prevents the breakdown and causes rapid buildup of the neurotransmitter acetylcholine at the synapse, resulting in a "cholinergic crisis" associated with numerous physiological symptoms, including excessive salivation, respiratory depression, bradycardia and prolonged seizures (status epilepticus, SE) (Bajgar, 2004; Hoffmann and Papendorf, 2006). These symptoms of POX exposure, if left untreated can result in the rapid demise of the OP exposed individuals (McDonough et al., 1995). Survivors of SE and OP compounds poisoning suffer from significant morbidities including spontaneous recurrent seizures, deficits in cognition and depression (Steenland et al., 1994; Garcia et al., 2003; Ruckart

et al., 2004; Johnson et al., 2009; de Araujo Furtado et al., 2010; de Araujo Furtado et al., 2012; Rauh et al., 2012; Terry et al., 2012). It is important to develop animal survival models for lethal exposures to evaluate treatments to reduce acute mortality and prevent chronic morbidity after exposure to potent OP agent.

There are studies reporting models of acute POX toxicity and survival shortly after exposure (Petrikovics et al., 2004; Albuquerque et al., 2006; Todorovic et al., 2012); however, to our knowledge there are no studies that evaluate long-term survival after lethal POX induced SE. The goal of this study is to further develop a reliable rat survival model for lethal POX exposure SE that will replicate both the acute and long-term effects of this agent. Such a model could be used screen medical countermeasures to improve survival and also help in studying molecular mechanisms underlying the development of long-term morbidity following OP exposures. Here 
we utilized POX to mimic lethal OP poisoning and have followed surviving animals for up to one year after POX intoxication. The mortality, behavioral manifestations and EEG profile for acute POX exposure are characterized in this study as evaluated for other nerve agent and pesticide exposures (McDonough and Shih, 1993; Shih et al., 2007; Deshpande et al., 2010). Our results show that POX exposure produced a reliable response mimicking all the signs and symptoms of OP intoxication. Development of this model resulted in high survival rates following lethal POX exposures as a result of an improved regimen of treatment with atropine, 2PAM and diazepam. This model could provide a reproducible method to mimic the human survival of POX toxicity.

It has been established that one of the long-term molecular changes that occurs following the survival of SE from either exposure to the OP DFP (Deshpande et al., 2010) or chemoconvulsant pilocarpine (Raza et al., 2004) is the development of sustained elevations in $\left(\left[\mathrm{Ca}^{2+}\right]_{\mathrm{i}}\right)$ termed the " $\mathrm{Ca}^{2+}$ plateau". These alterations in $\mathrm{Ca}^{2+}$ dynamics along with the associated neuronal injury are thought to underlie the chronic effects of SE on producing acquired epilepsy and behavioral and cognitive impairment (Rice et al., 1998; Raza et al., 2004; Deshpande et al., 2008b). This study will evaluate the effects of POX induced SE on the development of the $\mathrm{Ca}^{2+}$ plateau and neuronal damage to determine if the POX SE model produces similar effects on these processes as seen with pilocarpine and DFP SE. We will also investigate the contribution of ryanodine receptor (RyR) or inositol trisphosphate receptor $\left(\mathrm{IP}_{3} \mathrm{R}\right)$-dependent regulation of $\left[\mathrm{Ca}^{2+}\right]_{\mathrm{i}}$ towards the maintenance of the $\mathrm{Ca}^{2+}$ plateau utilizing select inhibitors that have been shown to lower elevated $\mathrm{Ca}^{2+}$ levels following SE (Nagarkatti et al., 2008; Nagarkatti et al., 2010). Being able to reverse the $\mathrm{Ca}^{2+}$ plateau after survival of POX $\mathrm{SE}$ with the $\mathrm{Ca}^{2+}$ induced $\mathrm{Ca}^{2+}$ release (CICR) inhibitors could provide new targets for the 
development of agents to reverse the $\mathrm{Ca}^{2+}$ plateau and offer a unique insight into the pathophysiology of POX toxicity.

\section{Materials and methods}

\section{Animals}

All animal use procedures were in strict accordance with the National Institute of Health Guide for the Care and Use of Laboratory Animals and approved by Virginia Commonwealth University’s Institutional Animal Care and Use Committee. Male Sprague-Dawley rats (Harlan,

Indianapolis, IN) weighing 250-300 $\mathrm{g}$ and 10-weeks age were used in this study. Animals were housed two per cage at $20-22^{\circ} \mathrm{C}$ with a 12 Light: 12 Dark hour cycle (lights on 0600-01800 h) and free access to food and water.

\section{Chemicals}

All the chemicals were obtained from Sigma Aldrich Company (St. Louis, MO) unless otherwise noted. POX was prepared by dissolving in ice-cold phosphate buffered saline (PBS) just before the experiment and injected subcutaneously (s.c.) and was kept on ice until the time of injections. Time on ice (between diluting in saline to injections) was never more than five minutes. Atropine sulfate and pralidoxime chloride (2-PAM) were dissolved in saline (0.9\% $\mathrm{NaCl}$ ) and sterile filtered. Diazepam injection-USP was obtained from VCU health system pharmacy. All the drugs were prepared fresh on the day of experiment. Dantrolene was dissolved in DMSO. It was applied to the neurons via bath perfusion. Response to dantrolene was recorded for up to 10 -mins following the bath perfusion. It took approximately $1 \mathrm{~min}$ for the complete exchange of bath solution. Levetiracetam tablets (Lupin; $250 \mathrm{mg}$ ) were obtained by VCU division of animal resources from local pharmacy. The water soluble tablets were crushed and 
dissolved in saline and sterile filtered to remove the non-soluble binding agents and pharmaceutical excipients before i.p. injection. Carisbamate (RWJ 333369) was a gift from Johnson \& Johnson, Pharmaceutical Research \& Development L.L.C. (Titusville, NJ, USA), and was suspended in $0.2 \%$ methylcellulose for i.p. administration.

\section{Electrode implantation and seizure monitoring}

Rats were stereotaxically implanted with three skull surface electrode screws attached to teflon insulated stainless steel MedWire® (Plastics One, Roanoke, VA, USA.) under general anesthesia with isoflurane/ $\mathrm{O}_{2}(5 \%$ induction; $2.5 \%$ maintenance). Electrode screws were positioned through burr holes above the right and left frontal cortices (AP, $3 \mathrm{~mm}$ and $\mathrm{ML}, \pm 3$ $\mathrm{mm}$ from bregma); the third surface electrode screw was positioned over the cerebellum to serve as reference and two additional (non-electrode) skull screws were inserted for structural support. The electrode screws were seated to contact, but not penetrate the dura mater. Female amphenol terminal pins connected to the electrode wire were seated into an electrode pedestal (Plastics One, Roanoke, VA) and this assembly was secured to the skull with Cerebond ${ }^{\mathrm{TM}}$ adhesive (Plastics One, Roanoke, VA). Rats were allowed 1 week of recovery time before the start of the experiment. Wire leads were securely connected into the threaded electrode pedestal on the rat and then connected to an electrical-swivel commutator (Plastics One, Roanoke, VA) to allow for free movement of the rat while maintaining continuity of EEG signals. EEG signals were amplified using a Grass model 8-10D (Grass Technologies, West Warwick, RI) and digitized using a Powerlab 16/30 data acquisition system (AD Instruments, Colorado Springs, CO). Evaluation of digitally acquired EEG was performed with Labchart (AD Instruments, Colorado Springs, CO) (Raza et al., 2004; Deshpande et al., 2010). 


\section{POX induced status epilepticus}

One minute following POX injection animals received 2-PAM (50 mg/kg, i.m.) and atropine (2 mg/kg, s.c.). Rats underwent convulsions and SE-like activity within 5-7 minutes following POX, and behavioral observations and Racine scores were made. Onset of SE was determined by the presence of continuous class 4-5 level seizures as assessed using a modified Racine scale (Racine, 1972), which were objectively and independently determined by three trained observers (Raza et al., 2004; Deshpande et al., 2010). Racine scores were averaged for each animal. Following onset of POX SE, animals were injected with diazepam (5 mg/kg, i.p.) and 2-PAM (25 mg/kg, i.m.) at 1, 3 and $5 \mathrm{~h}$ to terminate and control seizures. Surviving animals were then injected with saline (3cc/animal, i.p.) and fed lactose milk as part of supportive care and returned to home cage. Rats may lose up to 10-15 g weight due to fluid loss associated with SE. Animal health was reassessed every day for the next three days and wet-chow and saline was administered if weight gain did not occur. By the fourth-day all the SE rats had recovered from POX induced cholinergic crisis and were ambulatory. Surviving rats were housed individually in temperature and light controlled vivarium. All the rats were visually monitored once a week till their use in behavioral experiments. For $\mathrm{Ca}^{2+}$ studies, animals were sacrificed at $1 \mathrm{~h}$ following SE onset or at 1, 7 or 30 days after SE. Mortality was assessed at 24, 48 and 72-h. For

mechanism of $\mathrm{Ca}^{2+}$ plateau studies, levetiracetam $(50 \mathrm{mg} / \mathrm{kg}$, i.p. $)$ or carisbamate $(90 \mathrm{mg} / \mathrm{kg}$, i.p. $)$ was injected at 1, 6 and 18-h following onset of SE.

\section{Isolation of Hippocampal CA1 Neurons and Loading with Fura-2}

Acute isolation of CA1 hippocampal neurons was performed by established procedures (Raza et al., 2004; Deshpande et al., 2010). At specified times following onset of POX induced SE, animals were anesthetized with isoflurane and decapitated. Brains were rapidly dissected and 
placed in $4^{\circ} \mathrm{C}$ oxygenated $\left(95 \% \mathrm{O}_{2} / 5 \% \mathrm{CO}_{2}\right.$ ) artificial cerebrospinal fluid (aCSF) consisting of (in mM): 201.5 sucrose, 10 glucose, $1.25 \mathrm{NaH}_{2} \mathrm{PO}_{4}, 26 \mathrm{NaHCO}_{3}, 3 \mathrm{KCl}, 7 \mathrm{MgCl}_{2}$, and 0.2 $\left.\mathrm{CaCl}_{2}\right)$. MK-801 $(1 \mu \mathrm{M})$ was added to all solutions to increase cell viability and was removed 15 min prior to imaging. Hippocampal slices $(450 \mu \mathrm{m})$ were cut on a vibrating microtome (Leica Microsystems, Wetzlar, Germany) and then equilibrated for $10 \mathrm{~min}$ at $34^{\circ} \mathrm{C}$ in a piperazine-N,N'bis[2-ethanesulfonic acid] (PIPES)-aCSF solution containing (in $\mathrm{mM}$ ): $120 \mathrm{NaCl}, 25$ glucose, 20 PIPES, $5 \mathrm{KCl}, 7 \mathrm{MgCl}_{2}$, and $0.1 \mathrm{CaCl}_{2}$. Slices were then treated with $8 \mathrm{mg} / \mathrm{ml}$ protease in PIPES-aCSF for 6 min at $34^{\circ} \mathrm{C}$ and rinsed. Enzyme treated slices were visualized on a dissecting microscope to excise the CA1 hippocampal layer which was then triturated with a series of Pasteur pipettes of decreasing diameter in cold $\left(4^{\circ} \mathrm{C}\right)$ PIPES-aCSF solution containing $1 \mu \mathrm{M}$ Fura-2 AM (Invitrogen, Carlsbad, CA). The cell suspension was placed in the middle of 2 well glass-bottomed chambers (Nunc, Thermo Scientific). These glass chambers were previously treated overnight with $0.05 \mathrm{mg} / \mathrm{ml}$ poly-L-lysine followed by multiple rinses with distilled water and then further treated with Cell-Tak ${ }^{\top M}$ (BD-Biosciences, San Jose, CA) biocompatible cellular adhesive $\left(3.5 \mu \mathrm{g} / \mathrm{cm}^{2}\right)$ for 30-min, rinsed and air-dried. Neuronal suspension placed in the center of adhesive coated dishes when settled firmly adhered to the bottom. This technique simplified further manipulations on the dissociated neurons. Plates were then incubated at $37^{\circ} \mathrm{C}$ in a $5 \%$ $\mathrm{CO}_{2} / 95 \%$ air atmosphere for 45 min. Fura-2 was washed off with PIPES-aCSF and plates were incubated an additional 15 min to allow for complete cleavage of the AM moiety from Fura-2.

\section{Measurement of $\left[\mathrm{Ca}^{2+}\right]_{\mathrm{i}}$}

Fura-2 loaded cells were transferred to a $37^{\circ} \mathrm{C}$ heated stage (Harvard Apparatus, Hollington, MA) on an Olympus IX-70 inverted microscope coupled to a fluorescence imaging system (Olympus America, Center Valley, PA) and subjected to $\left[\mathrm{Ca}^{2+}\right]_{\mathrm{i}}$ measurements by 
procedures well established in our laboratory (Raza et al., 2004; Deshpande et al., 2010). All experiments were performed using a 20X, 0.7 N.A. water immersion objective and images were recorded by an ORCA-ER high-speed digital CCD camera (Hammamatsu Photonics K.K., Japan). Fura-2 was excited with a $75 \mathrm{~W}$ xenon arc lamp (Olympus America, Center Valley, PA). Ratio images were acquired by alternating excitation wavelengths (340/380 $\mathrm{nm}$ ) by using a Lambda 10-2 filter wheel (Sutter Instruments Co., Novato, CA) and a Fura filter cube at 510/540 emission with a dichroic at $400 \mathrm{~nm}$. All image acquisition and processing was controlled by a computer connected to the camera and filter wheel using Metafluor Software ver 7.6 (MDS Analytical Technologies, Downington, PA). Image pairs were captured every $5 \mathrm{~s}$ and the images at each wavelength were averaged over 10 frames. Background fluorescence was obtained by imaging a field lacking Fura-2.

Hippocampal CA1 neurons were identified based on their distinct morphology. These neurons displayed pyramidal shaped cell body, long axon and dendrites and have been demonstrated to be devoid of immunoreactivity for specific protein markers for interneurons, including parvalbumin, cholecystokinin, vasoactive intestinal peptide, somatostatin, and neuropeptide Y (Raza et al., 2004; Deshpande et al., 2010). The process of enzymatic treatment and mechanical trituration can add minimal stress during acute dissociation of neurons. However, we have shown previously that the neurons isolated using these procedures exhibit electrophysiological properties identical neurons in slices or in cultures (Raza et al., 2007), are viable, and not apoptotic or necrotic (Sun et al., 2008).

\section{Calcium calibration}

We performed $\mathrm{Ca}^{2+}$ calibration determinations as described previously (Raza et al., 2004; Deshpande et al., 2010) to provide estimates of absolute $\left[\mathrm{Ca}^{2+}\right]_{\mathrm{i}}$ concentrations from the $340 / 380$ 
ratio values. $\mathrm{A} \mathrm{Ca}^{2+}$ calibration curve was constructed using solutions of calibrated $\mathrm{Ca}^{2+}$ buffers ranging from $0 \mathrm{Ca}^{2+}\left(\mathrm{Ca}^{2+}\right.$ free) to $39 \mu \mathrm{M} \mathrm{Ca}^{2+}$ (Invitrogen, Carlsbad, CA). Values from the calibration curve were used to convert fluorescent ratios to $\left[\mathrm{Ca}^{2+}\right]_{\mathrm{i}}$. Final $\left[\mathrm{Ca}^{2+}\right]_{\mathrm{i}}$ were calculated from the background corrected 340/380 ratios using the equation (Grynkiewicz et al., 1985):

$$
\left[\mathrm{Ca}^{2+}\right]_{\mathrm{i}}=\left(\mathrm{K}_{\mathrm{d}} \times \mathrm{Sf}_{2} / \mathrm{Sb}_{2}\right) \times\left(\mathrm{R}-\mathrm{R}_{\min }\right) /\left(\mathrm{R}_{\max }-\mathrm{R}\right)
$$

where $\mathrm{R}$ is the $340 / 380$ ratio at any time; $\mathrm{R}_{\max }$ is the maximum measured ratio in saturating $\mathrm{Ca}^{2+}$ solution $\left(39 \mu \mathrm{M}\right.$ free $\left.\mathrm{Ca}^{2+}\right) ; \mathrm{R}_{\min }$ is the minimal measured ratio $\mathrm{Ca}^{2+}$ free solution; $\mathrm{Sf}_{2}$ is the absolute value of the corrected 380-nm signal at $\mathrm{Rmin} ; \mathrm{Sb}_{2}$ is the absolute value of the corrected 380-nm signal at $\mathrm{R}_{\max }$; the $\mathrm{K}_{\mathrm{d}}$ value for Fura 2 is $224 \mathrm{nM}$.

\section{Fluoro-Jade staining}

Animals were sacrificed 48-h following POX exposure and received all the antidotes at the appropriate times as outlined in POX SE section above. Briefly, deep anesthesia was induced in rats with ketamine/xylazine $(75 \mathrm{mg} / \mathrm{kg} / 7.5 \mathrm{mg} / \mathrm{kg}$ i.p.) mixture. Anesthetized animals were flushed transcardially with saline and perfused with $4 \%$ paraformaldehyde in a $100 \mathrm{mM}$ sodium phosphate buffer (pH 7.4). Fixed brains were removed and post-fixed in $4 \%$ paraformaldehyde/phosphate buffer overnight, cryoprotected in 30\% sucrose/phosphate buffer (pH 7.4) (48 h), flash frozen in isopentane and stored at $-80^{\circ} \mathrm{C}$ until used for sectioning. Coronal sections $(40 \mu \mathrm{m})$ were cut on a cryostat (Leica Microsystems, Wetzlar, Germany) and stored at $20^{\circ} \mathrm{C}$ in a cryoprotectant solution of $0.1 \mathrm{M}$ phosphate buffer containing $30 \%$ sucrose, $30 \%$ ethylene glycol and 1\% polyvinyl-pyrrolidone (PVP-40). Sections were washed three times in a $0.1 \%$ triton in PBS and then float-mounted onto microscope slides (Trubond 380; Tru Scientific LLC, Bellingham, WA) and allowed to dry at room temperature overnight prior to staining. 
Slides were incubated in a solution of $1 \% \mathrm{NaOH}$ in $80 \%$ ethanol for 5 minutes followed by hydration in a $70 \%$ ethanol and then $\mathrm{ddH}_{2} \mathrm{O}$ for 2 minutes each. Slides were then incubated in a $0.06 \% \mathrm{KMnO}_{4}$ solution for 10 min followed by washing in $\mathrm{ddH}_{2} \mathrm{O}$ for $2 \mathrm{~min}$. Slides were then stained in a $0.0004 \%$ fluoro-Jade C solution in $0.1 \%$ acetic acid for $20 \mathrm{~min}$. Stained slides underwent three washes in $\mathrm{ddH}_{2} \mathrm{O}$ for 2 min each and then dried in a desiccant chamber at $55^{\circ} \mathrm{C}$ for 30 min. Stained slides were then cleared with xylene for 5 min and cover slipped with DPX mounting agent (Sigma Chem. Co., St. Louis, MO). Stained sections were evaluated with a fluorescent IX70 inverted microscope with a 20X (UApo 340, 0.7 n.a., water) objective (Olympus America, Center Valley, PA) and excitation/emission filters for visualization of FITC. Greyscale digital images (1324x1024, 16-bit, 1X1 binning) of Fluoro-Jade C staining for select brain regions including dentate gyrus hilus, were acquired with a Hamamatsu ORCA-ER camera (Hamamatsu Photonics, Japan).

\section{Data analysis}

In dose-response experiments, the response to POX is expressed as the percentage of animals exhibiting $\mathrm{SE}$ or mortality. $\mathrm{LD}_{50}$ values representing the estimated doses causing $\mathrm{SE}$ or mortality in 50\% of animals with their 95\% confidence limits (95\% CL) were determined by logprobit analysis using the Litchfield and Wilcoxon method.

For comparison of $\left[\mathrm{Ca}^{2+}\right]_{\mathrm{i}}$ between sham and POX-treated animals, Student's $t$-test or One Way Analysis of Variance (ANOVA) was applied when appropriate to compare $\left[\mathrm{Ca}^{2+}\right]_{\mathrm{i}}$. The Tukey test was used for all post-hoc comparisons. For comparing the distributions of $\left[\mathrm{Ca}^{2+}\right]_{\mathrm{i}}$ levels a Chi-square test was used. Statistical tests were run and graphs generated with SigmaPlot 12.5 (SPSS Inc, Chicago, IL). p $<0.05$ was considered significant. 
We used 5-9 animals for each experimental condition or time point studied. Dissociating the hippocampal slices routinely yielded 20-25 healthy, phase-bright neurons that were used for the recordings. The means of each group of neurons from each animal were used to evaluate results and conduct statistical analysis. Viable neurons included in the study had a smooth surface and a pyramidal-like morphology with processes. Non-viable neurons were swollen or circular and the surface was uneven and irregular. Data from each animal were pooled together in respective groups and ultimately represented as total number of cells studied.

Analysis of digital images to count FluoroJade C positive cell staining was carried out with ImageJ (ImageJ, U. S. National Institutes of Health, Bethesda, MD) by thresholding for specific stain and obtaining positive cell counts using the particle analysis component (size range in pixel: 25-1000). All parameters for digital acquisition and analysis of staining remained constant throughout. Representative digital images were processed with Adobe Photoshop for figures (Adobe Systems Inc., San Jose, CA).

\section{Results}

\section{Effects of POX administration}

Paraoxon (POX, 0.1-4 mg/kg, s.c., $\mathrm{n}=5-8$ ) was injected and behavioral responses were observed. Rats manifested gross behavioral changes such as increased grooming, sniffing and chewing that were rapidly followed by tremors, wet-dog shakes and Straub tail response. Cholinergic symptoms appeared shortly thereafter which included respiratory distress (croaking, bradypnea), ex-opthalmus, salivation, defecation and urination. Following higher doses of POX, tonic-clonic seizures appeared and rats rapidly went into status epilepticus (SE). Without antidotal treatment of the severe cholinergic crisis, death ensued rapidly in all POX SE animals, demonstrating the lethal effects of this dose of POX exposure. POX induced a dose-dependent 
increase in the incidence of SE and mortality. The LD 50 for induction of seizure was $0.39 \mathrm{mg} / \mathrm{kg}$ (95\% CL: 0.32-0.47) and for mortality it was $0.85 \mathrm{mg} / \mathrm{kg}$ (95\% CL: 0.32-2.19). In addition, the time to onset of POX SE was also dose-dependent. At low dose $(0.5 \mathrm{mg} / \mathrm{kg})$ it was $18.7 \pm 1.1$ min, whereas at high dose $(4 \mathrm{mg} / \mathrm{kg})$ it was $3.2 \pm 0.2 \mathrm{~min}$. The seizure responses were scored on a five point Racine scale (see methods). At doses $1 \mathrm{mg} / \mathrm{kg}$ and above a maximum Racine score of 5 was noted. At low POX doses not associated with mortality, animals spent 40 min in SE in a 1h observation period. At POX doses associated with mortality, the time of death was also dosedependent. This data is summarized in Table 1 and 2.

\section{Effects of atropine, 2-PAM and diazepam following acute POX poisoning}

The three drug regimen consisting of atropine to treat cholinergic symptoms, 2-PAM as an antidote to AChE inhibition and diazepam for stopping seizures is FDA approved for OP poisoning and being used by military to treat nerve agent exposure (Chemical Hazards Emergency Medical Management, 2013). We investigated the efficacy of these agents in our rat model of lethal POX poisoning. For these experiments we tested the highest dose of POX (4 $\mathrm{mg} / \mathrm{kg}$ ) as this ensured that $100 \%$ animals would undergo SE and without intervention resulted in $100 \%$ mortality. Such criteria allowed for rigorous testing of the three drug intervention. Mortality was assessed at 1-h, 24-h, 48-h and 72-h following POX injection.

Atropine (2 mg/kg, saline, i.p.) was injected 1-min after POX injection (4 mg/kg, ice-cold PBS, s.c.). All rats ( $n=24)$ went into SE. Mortality was 30\% 1-h after SE. At 24-h following SE, mortality was $60 \%$ and it was $70 \%$ and $90 \%$ at 48 and 72 -h respectively. Thus, while atropine relieved the cholinergic symptoms and helped in reducing early mortality, the progressive AChE inhibition and SE still led to significant mortality. 
Rats $(\mathrm{n}=24)$ were then injected with 2-PAM (25 mg/kg, saline, i.m.) along with atropine ( $2 \mathrm{mg} / \mathrm{kg}$, i.p.) 1-min after POX injection (4 mg/kg, s.c.). Mortality was almost halved to $15 \% 1$ $\mathrm{h}$ after SE when 2-PAM was introduced. At 24-h following SE, mortality was $50 \%$ and it was $60 \%$ and $80 \%$ at 48 and 72-h respectively. Thus, while atropine and 2-PAM administration dramatically lowered the early mortality, the unremitting seizures and SE led to greater mortality in the subsequent days. Racine scores were not affected in the presence of the atropine and 2PAM either alone or in combination suggesting that these agents did not affect severity of SE.

Rats $(\mathrm{n}=24)$ were administered diazepam $(5 \mathrm{mg} / \mathrm{kg}$, i.p. $)$ at 1, 3 and 5-h following POX (4 mg/kg, s.c.) induced SE, in addition to atropine and 2-PAM administration 1-min following POX injection. Mortality rate of $12 \%$ at $1-\mathrm{h}$ following POX induced SE was in a similar range as observed above. However, when the SE was terminated with sequential diazepam injections, mortality was dramatically reduced to $8 \%$ at $24-\mathrm{h}$ and $17 \%$ at 48 and $72-\mathrm{h}$. These findings suggested that stopping the OP induced SE is critical to reduce the mortality and improve longterm survival. This survival data has been summarized in Table 3. Rats surviving lethal POX exposure at the 72-h time point were returned to the vivarium and housed one per cage. POX treated rats were re-assessed for mortality at 3,6 and 12-months post rescue from POX SE. Taking into account the normal age-related attritions $(<5 \%)$ in our rat populations, no further increases in mortality were observed in POX SE survivors. Thus, this lethal POX survival model is ideally suited to prepare animals to study long term effects of POX exposure.

\section{EEG characterization of POX induced SE}

POX induced seizures were also confirmed with EEG recordings. Baseline EEG was recorded for 30-min before POX injection (4 mg/kg, s.c.). A representative recording is shown in Fig. 1. POX induced seizure onset was very rapid and the tonic-clonic seizure activity occurred 
in parallel with high rhythmic epileptiform EEG activity as shown in Fig 1a (expanded portion). Within 7-8 minutes, animals progressed into electrographic SE. The SE was intense, did not wax or wane and did not lose its intensity throughout the one-hour of seizure activity displaying 7-10 $\mathrm{Hz}$ spike activity (Fig. 1a). Animals were injected with diazepam (5 mg/kg) plus 2-PAM (25 $\mathrm{mg} / \mathrm{kg}$ ) at 1, 3 and 5-h following onset of POX SE. This dose of diazepam was effective in completely terminating both behavioral and electrographic SE (Fig. 1, DZP). The EEG pattern for SE termination for up to 24-h following diazepam is shown in Fig. 1. It demonstrates the effectiveness of optimized 3-dose regimen in that seizures remained suppressed upon drug intervention and did not reoccur in days following SE termination.

The electrophysiological progression of POX induced SE is depicted in Fig. 2. EEG alterations following POX administration were rapid and correlated with behavioral seizure manifestations. Fig. 2A shows a baseline EEG recording before POX injection. Low-voltage fast activity started to appear within 2-3 min of POX administration (Fig. 2B). High-voltage slow activity (Fig. 2C) appeared shortly thereafter and rapidly progressed into high-voltage spiking in correlating with behavioral seizure activity by approximately 5-6 minutes (Fig. 2E). By this time animals were in electrographic SE with fully developed seizures. SE continued unabated for one hour, after which time they were terminated using sequential diazepam injections.

\section{POX induced SE caused elevations in hippocampal neuronal $\left[\mathrm{Ca}^{2+}\right]_{\mathrm{i}}$}

To investigate if POX exposure caused long lasting changes in hippocampal neuronal

$\left[\mathrm{Ca}^{2+}\right]_{\mathrm{i}}$, similar to other OPs and chemoconvulsants (Raza et al., 2004; Deshpande et al., 2010), we measured neuronal $\left[\mathrm{Ca}^{2+}\right]_{i}$ after 1-h of SE using the high affinity, ratiometric $\mathrm{Ca}^{2+}$ indicator Fura-2 in acutely isolated hippocampal neurons from control and POX exposed SE animals. Representative pseudocolor images of neurons from control and POX-SE rats are shown in Fig. 
3A. Acutely isolated CA1 hippocampal neurons harvested from animals that underwent 1-h POX induced SE manifested mean $\left[\mathrm{Ca}^{2+}\right]_{\mathrm{i}}$ of $675 \pm 48 \mathrm{nM}$ ( $\mathrm{n}=6$ animals), were significantly higher than $\left[\mathrm{Ca}^{2+}\right]_{\mathrm{i}}$ in neurons harvested from age-matched controls $(163 \pm 16 \mathrm{nM}, \mathrm{n}=5$ animals $)$ as shown in Fig. 3B ( $<<0.001, t$-test).

Analysis of the population distributions of $\left[\mathrm{Ca}^{2+}\right]_{\mathrm{i}}$ revealed only $5 \%$ of control neurons exhibited $\left[\mathrm{Ca}^{2+}\right]_{i}$ greater than $500 \mathrm{nM}$, with the majority of neurons falling into the lower $\mathrm{Ca}^{2+}$ concentration range. In contrast, approximately $60 \%$ neurons isolated from POX SE rats exhibited $\left[\mathrm{Ca}^{2+}\right]_{\mathrm{i}}$ greater than $500 \mathrm{nM}$ indicating a population shift towards higher $\mathrm{Ca}^{2+}$ concentration range. This rightward shift in distribution of $\left[\mathrm{Ca}^{2+}\right]_{\mathrm{i}}$ levels in POX SE neurons was significantly different from control neurons (Fig. 4, $\mathrm{p}<0.001$, Chi-square test, $\mathrm{n}=136$ neurons).

\section{Development of calcium plateau following POX induced SE}

To investigate the duration of elevated hippocampal $\left[\mathrm{Ca}^{2+}\right]_{\mathrm{i}}$ following the termination of POX induced SE, we measured $\left[\mathrm{Ca}^{2+}\right]_{\mathrm{i}}$ at various time points for up to one month. As shown in Fig. 5, at 1, 7 and 30-days following SE termination, $\left[\mathrm{Ca}^{2+}\right]_{\mathrm{i}}$ (in $\mathrm{nM}$ ) were $514 \pm 14,483 \pm 32$ and $406 \pm 28$ respectively. These values were significantly higher than $\left[\mathrm{Ca}^{2+}\right]_{\mathrm{i}}$ of neurons harvested from age-matched control rats ( $\mathrm{p}<0.001$, one-way ANOVA, $\mathrm{n}=6$ animals). These results demonstrate that POX SE in this model produced sustained elevations in intracellular $\mathrm{Ca}^{2+}$-concentrations $\left(\mathrm{Ca}^{2+}\right.$ plateau).

\section{Mechanism for calcium plateau following POX induced SE}

We have demonstrated that SE leads to development of $\mathrm{Ca}^{2+}$ plateau (Raza et al., 2004; Deshpande et al., 2010) that has its origins in $\mathrm{Ca}^{2+}$ release from intracellular stores (Nagarkatti et al., 2010). To investigate contribution of intracellular CICR receptors in the development of 
POX $\mathrm{Ca}^{2+}$ plateau, $\left[\mathrm{Ca}^{2+}\right]_{\mathrm{i}}$ were measured in neurons obtained from POX SE rats in the presence of RyR blocker dantrolene (Nagarkatti et al., 2010). As shown in Fig. 6, application of dantrolene $(50 \mu \mathrm{M})$ to hippocampal neurons isolated from rats 24-h following POX SE resulted in a significant drop in $\left[\mathrm{Ca}^{2+}\right]_{\mathrm{i}}$ from $514 \pm 14 \mathrm{nM}$ (no drug) to $324 \pm 24 \mathrm{nM}(\mathrm{p}<0.01, \mathrm{n}=5$ rats). This represent almost $60 \%$ reduction in $\left[\mathrm{Ca}^{2+}\right]_{i}$ following dantrolene application suggesting that RyRs are significantly contributing to maintaining the POX SE induced $\mathrm{Ca}^{2+}$ elevations.

Following the efficacy of dantrolene in lowering POX SE induced $\mathrm{Ca}^{2+}$ elevations in vitro, we next investigated the effects of in vivo administration of levetiracetam and carisbamate. We have shown these drugs to target $\mathrm{RyR} / \mathrm{IP}_{3}$ receptors and also produce an antiepileptogenic response following SE-like injury (Deshpande et al., 2008a; Nagarkatti et al., 2008). As shown in Fig. 6, $\left[\mathrm{Ca}^{2+}\right]_{\mathrm{i}}$ in hippocampal neurons isolated from rats treated with three doses of levetiracetam (50 mg/kg, i.p., 1, 6 and 18-h post POX SE onset) were $290 \pm 10 \mathrm{nM}$ that were significantly lower than $\left[\mathrm{Ca}^{2+}\right]_{\mathrm{i}}$ in neurons isolated from untreated POX SE rats $(\mathrm{p}<0.001, \mathrm{n}=5$ rats). Similarly, $\left[\mathrm{Ca}^{2+}\right]_{\mathrm{i}}$ in hippocampal neurons isolated from rats treated with three doses of carisbamate (90 mg/kg, i.p., 1, 6 and 18-h post SE onset) were $348 \pm 26 \mathrm{nM}$ that were significantly lower than $\left[\mathrm{Ca}^{2+}\right]_{\mathrm{i}}$ in neurons isolated from untreated POX SE rats $(\mathrm{p}<0.001, \mathrm{n}=5$ rats) as shown in Fig. 6.

\section{Neuronal injury associated with acute POX intoxication}

To assess neuronal injury in animals surviving exposure, brain sections from animals injected with POX or vehicle were labeled with Fluoro-Jade C (FJC) (Li et al., 2011). Across all brain regions examined, there was negligible FJC labeling in brain sections obtained from vehicle controls. In contrast, after POX treatment, FJC-positive cells were observed in select regions throughout the forebrain. Within the hippocampus, FJC-positive staining was observed 
in the polymorphic layer and along the hilus/granule cell border of the dentate gyrus.

Additionally, FJC-positive stained neurons were observed throughout layers II and III of the parietal cortex (Fig. 7A). The quantification of the neuronal injury expressed as FJC positive cells is shown in Fig. 7B.

\section{Discussion}

The ready availability of pesticides and other toxic agricultural and industrial chemicals make these agents attractive target for terrorists to weaponize them and cause civilian causalities (Federation of American Scientists, 1998; Gould and Folb, 2003; Central Intelligence Agency, 2004; Croddy et al., 2004; Moorcraft and McLaughlin, 2008). It is therefore important to study mechanisms for reducing mortality and morbidity upon exposure to OP agents. Compounds like DFP and POX mimic the actions of sarin, soman and VX, and are therefore utilized in a controlled experimental setting to model the effects of nerve agent exposure in civilian laboratories (Kadriu et al., 2009; Wright et al., 2009; Zaja-Milatovic et al., 2009; Deshpande et al., 2010; Li et al., 2011; Todorovic et al., 2012). The POX lethal exposure and survival model optimized in this study provides an ideal animal model to develop medical counter measures to POX toxicity in a reliable and cost effective manner. Our survival model after lethal POX exposure offers a valuable contribution to the field by providing a reproducible system to study the chronic effects of POX toxicity and the development of OP exposure co-morbidities. In addition, this study demonstrates comparable findings to other OP agents such as DFP (Kadriu et al., 2009; Wright et al., 2009; Zaja-Milatovic et al., 2009; Deshpande et al., 2010; Li et al., 2011), the chemoconvulsant pilocarpine (Raza et al., 2004), and chemical threat agents such as Tetramethylenedisulfotetramine (TETS) (Cao et al., 2012), that POX exposure produces elevated neuronal $\left[\mathrm{Ca}^{2+}\right]_{\mathrm{i}}$ and injury. These changes in intracellular $\mathrm{Ca}^{2+}$ concentrations 
persisted for over a month following the termination of POX SE, and in combination with the observed with the multifocal neuronal injury, may underlie some of the long-term effects of OP toxicity on neuronal function and behavioral impairments (DeLorenzo et al., 2005; Filbert et al., 2005; de Araujo Furtado et al., 2012). Furthermore, identification of mechanisms responsible for injury-induced $\mathrm{Ca}^{2+}$ plateau may elucidate novel targets and candidate drugs for the potential treatment of long-term morbidity associated with POX and other OP exposures.

Following high dosages of POX, the enzyme AChE is rapidly inhibited, resulting in a massive buildup of acetylcholine at the synapses. A cholinergic crisis ensues that result in the progression of bradypnea, bradycardia and convulsions, followed by rapid death (Bajgar, 2004; Hoffmann and Papendorf, 2006). The three drug regimen presented in this study consisting of atropine, 2-PAM and diazepam is FDA approved and used by US military (Mark I kit), and is the mainstay treatment for OP poisoning/ nerve agent toxicity (Chemical Hazards Emergency Medical Management, 2013). A higher survival rate was obtained following lethal POX exposures by optimizing the standard three drug regimens used for treating OP poisoning. The mortality following lethal POX intoxication was most effectively reduced by atropine, in agreement with previous nerve agent studies (Shih et al., 2007). A lower dose of atropine (0.1$0.2 \mathrm{mg} / \mathrm{kg}$ ), similar to auto injector doses used in human pre-exposure situations for OP intoxication, was effective in reducing mortality by $20 \%$ in our animal model (data not shown). However, since we wanted to develop an animal model of lethal OP exposure survival in order to study long-term morbidities, we increased atropine concentration to $2 \mathrm{mg} / \mathrm{kg}$. This higher dose of atropine, along with 2-PAM and diazepam intervention, resulted in a significantly higher survival rate of $85 \%$. This is in line with findings from our previous report following lethal DFP exposure (Deshpande et al., 2010). Our results show that while each drug by itself is critical to 
limit acute mortality, stopping the SE with diazepam is by far the most important intervention to significantly reduce long-term mortality. This is in agreement with the clinical literature that reports a high mortality in patients undergoing SE (DeLorenzo et al., 2009).

POX induced SE produced prolonged elevations in neuronal $\mathrm{Ca}^{2+}$ concentrations similar to those seen with DFP and pilocarpine (Raza et al., 2004; Deshpande et al., 2010). These elevations were sustained and lasted for up to one-month following the termination of SE. This $\mathrm{Ca}^{2+}$ plateau had its origin in $\mathrm{Ca}^{2+}$ release from intracellular stores, since intervention with CICR receptor inhibitors dantrolene (Nagarkatti et al., 2010) or levetiracetam (Nagarkatti et al., 2008) abolished the $\mathrm{Ca}^{2+}$ plateau when administered in vitro or in vivo. The $\mathrm{Ca}^{2+}$ plateau following SE is thought to trigger plasticity changes during the period of epileptogenesis that ultimately results in the development of acquired epilepsy (DeLorenzo et al., 2005). Indeed, treatment with the purported antiepileptogenic agent carisbamate prevented the development of spontaneous epileptiform discharges in hippocampal neurons following SE (Deshpande et al., 2008a). These epileptiform discharges are a result of altered $\mathrm{Ca}^{2+}$ dynamics following SE-like injury (DeLorenzo et al., 2005). In line with these studies, treatment with carisbamate lowered POX SE mediated elevations in intracellular $\mathrm{Ca}^{2+}$ levels. It will be interesting to evaluate if $\mathrm{Ca}^{2+}$ levels revert back to higher concentrations following removal of drugs. This may necessitate multiple drug injections to maintain lower $\mathrm{Ca}^{2+}$ levels post $\mathrm{SE}$ in order to prevent development of $\mathrm{Ca}^{2+}$ mediated altered synaptic plasticity.

It has been demonstrated that $\mathrm{SE}$ is associated with significant cell death in various brain regions (DeLorenzo et al., 2005). This neuronal death is thought to be $\mathrm{Ca}^{2+}$ dependent since manipulations that lower neuronal $\mathrm{Ca}^{2+}$ entry before or during $\mathrm{SE}$ are effective in producing significant neuroprotection. Thus, NMDA receptor antagonist MK-801 given before SE prevents 
the protracted elevations in $\left[\mathrm{Ca}^{2+}\right]_{\mathrm{i}}$ inhibits epileptogenesis and other $\mathrm{SE}$ related morbidities (Rice et al., 1998; Raza et al., 2004; DeLorenzo et al., 2005; Deshpande et al., 2010). We have also demonstrated that while NMDA receptor mediated $\mathrm{Ca}^{2+}$ entry is essential for generation of the $\mathrm{Ca}^{2+}$ plateau; it does not play a role in its maintenance (Raza et al., 2004; Deshpande et al., 2010). Thus, MK-801 administered 1-h after SE cannot prevent the development of $\mathrm{Ca}^{2+}$ plateau and does not afford neuroprotection (Raza et al., 2004; DeLorenzo et al., 2005). However, CICR from intracellular stores contributes to the maintenance of the $\mathrm{Ca}^{2+}$ plateau such that inhibition of RyRs not only abolishes $\mathrm{Ca}^{2+}$ plateau, but it also prevents the development of SE-like injury induced spontaneous epileptiform discharges in hippocampal neurons in vitro (Nagarkatti et al., 2010). We hypothesize that it is this $\mathrm{Ca}^{2+}$ entry occurring during $\mathrm{SE}$ and not the $\mathrm{Ca}^{2+}$ plateau generated after one-hour of SE that contributes to neuronal death. It will be interesting to investigate if the other brain regions associated with neuronal death also manifest similar $\mathrm{Ca}^{2+}$ elevations. The CICR agents used in this study are administered one-hour after SE at which point they may not be able to prevent the on-going neuronal death processes. However, by inhibiting the sustained $\mathrm{Ca}^{2+}$ elevations post $\mathrm{SE}$ we predict that they may be able lower the morbidities associated with SE. This possibility is currently being evaluated by our laboratory.

We have observed POX intoxicated rats for up to one-year following their rescue with the three-drug regimen optimized in this study. After taking into consideration the normal agerelated attrition in the population of rats housed in our vivarium, we did not observe increases in mortality percentage in POX SE rescued rats. To our knowledge this is the first study that has followed the mortality in rats surviving lethal POX exposure for an extended period of time out to one year. An SE survival model of POX intoxication should also exhibit long-term consequences of OP exposure indicative of cognitive deficits and co-morbidities (Steenland et 
al., 1994; Brown and Brix, 1998; Ivens et al., 1998; Wesseling et al., 2002; Ruckart et al., 2004; Edwards and Tchounwou, 2005; de Araujo Furtado et al., 2012; Terry et al., 2012). In our preliminary results we have observed the development of chronic seizures, depressive symptoms and memory impairments in POX SE survivor rats (data not shown). The complete assessment of chronic neurological disorders in POX survivors is currently underway in our laboratory. However, these preliminary observations further validate our proposed model.

We have demonstrated that CNS injuries such as SE, stroke or traumatic brain injury result in neuronal injury and protracted elevations in hippocampal $\left[\mathrm{Ca}^{2+}\right]_{\mathrm{i}}$ (Rice et al., 1998; Raza et al., 2004; Deshpande et al., 2008b; Deshpande et al., 2010). Since $\mathrm{Ca}^{2+}$ is a major second messenger molecule, such sustained increases in its levels activate multiple signaling cascades, affect protein transcription and alter gene expression of proteins involved in controlling membrane excitability and synaptic plasticity (DeLorenzo et al., 2005). These $\mathrm{Ca}^{2+}$ mediated alterations are thought to underlie the long-term morbidity following CNS insults (DeLorenzo et al., 2005; Deshpande et al., 2008b). OP exposure has been reported to be associated with neurological problems such as seizures, cognitive deficits and other behavioral disorders (de Araujo Furtado et al., 2010; de Araujo Furtado et al., 2012). Inhibition of the POX SE induced $\mathrm{Ca}^{2+}$ plateau with a regimen of FDA approved drugs could prove to be novel countermeasure agents to potentially prevent the morbidity associated with OP poisoning. 


\section{Funding}

This work was supported by the CounterACT Program, National Institutes of Health Office of the Director (NIH OD), and the National Institute of Neurological Disorders and Stroke [Grant Number U01NS058213 and R21NS072061] to RJD. Its contents are solely the responsibility of the authors and do not necessarily represent the official views of the federal government. 


\section{References:}

Albuquerque, E.X., Pereira, E.F., Aracava, Y., Fawcett, W.P., Oliveira, M., Randall, W.R., Hamilton, T.A., Kan, R.K., Romano, J.A., Jr., Adler, M., 2006. Effective countermeasure against poisoning by organophosphorus insecticides and nerve agents. Proc Natl Acad Sci U S A 103, $13220-13225$.

Bajgar, J., 2004. Organophosphates/nerve agent poisoning: mechanism of action, diagnosis, prophylaxis, and treatment. Adv Clin Chem 38, 151-216.

Brown, M.A., Brix, K.A., 1998. Review of health consequences from high-, intermediate- and low-level exposure to organophosphorus nerve agents. J Appl Toxicol 18, 393-408.

Cao, Z., Hammock, B.D., McCoy, M., Rogawski, M.A., Lein, P.J., Pessah, I.N., 2012. Tetramethylenedisulfotetramine alters $\mathrm{Ca}(2)(+)$ dynamics in cultured hippocampal neurons: mitigation by NMDA receptor blockade and GABA(A) receptor-positive modulation. Toxicol Sci 130, 362-372.

Central Intelligence Agency, 2004. Terrorist CBRN: Materials and Effects.

Chemical Hazards Emergency Medical Management, 2013. Nerve Agents - Emergency Department/Hospital Management, pp.

Croddy, E., Wirtz, J., Larsen, J., 2004. Weapons of Mass Destruction: An Encyclopedia of Worldwide Policy, Technology, and History ABC-CLIO, Santa Barbara, CA.

de Araujo Furtado, M., Lumley, L.A., Robison, C., Tong, L.C., Lichtenstein, S., Yourick, D.L., 2010. Spontaneous recurrent seizures after status epilepticus induced by soman in SpragueDawley rats. Epilepsia 51, 1503-1510.

de Araujo Furtado, M., Rossetti, F., Chanda, S., Yourick, D., 2012. Exposure to nerve agents: from status epilepticus to neuroinflammation, brain damage, neurogenesis and epilepsy. Neurotoxicology 33, 1476-1490.

DeLorenzo, R.J., Kirmani, B., Deshpande, L.S., Jakkampudi, V., Towne, A.R., Waterhouse, E., Garnett, L., Ramakrishnan, V., 2009. Comparisons of the mortality and clinical presentations of status epilepticus in private practice community and university hospital settings in Richmond, Virginia. Seizure 18, 405-411.

DeLorenzo, R.J., Sun, D.A., Deshpande, L.S., 2005. Cellular mechanisms underlying acquired epilepsy: the calcium hypothesis of the induction and maintainance of epilepsy. Pharmacol Ther 105, 229-266.

Deshpande, L.S., Carter, D.S., Blair, R.E., DeLorenzo, R.J., 2010. Development of a prolonged calcium plateau in hippocampal neurons in rats surviving status epilepticus induced by the organophosphate diisopropylfluorophosphate. Toxicol Sci 116, 623-631. 
Deshpande, L.S., Nagarkatti, N., Ziobro, J.M., Sombati, S., DeLorenzo, R.J., 2008a. Carisbamate prevents the development and expression of spontaneous recurrent epileptiform discharges and is neuroprotective in cultured hippocampal neurons. Epilepsia 49, 1795-1802.

Deshpande, L.S., Sun, D.A., Sombati, S., Baranova, A., Wilson, M.S., Attkisson, E.A., Hamm, R.J., Delorenzo, R.J., 2008b. Alterations In Neuronal Calcium Levels Are Associated With Cognitive Deficits After Traumatic Brain Injury. Neurosci Lett 441, 115-119.

Edwards, F.L., Tchounwou, P.B., 2005. Environmental toxicology and health effects associated with methyl parathion exposure--a scientific review. Int J Environ Res Public Health 2, 430-441.

Federation of American Scientists, 1998. Truth and Reconciliation Commission. FINAL REPORT: Volume TWO Chapter SIX. Presented to President Nelson Mandela on 29 October 1998.

Filbert, M., Levine, E., Ballough, G., 2005. Neuroprotection for nerve agent-induced brain damage by blocking delayed calcium overload: a review J Med CBR Def 3.

Garcia, S.J., Abu-Qare, A.W., Meeker-O'Connell, W.A., Borton, A.J., Abou-Donia, M.B., 2003. Methyl parathion: a review of health effects. J Toxicol Environ Health B Crit Rev 6, 185-210.

Gould, C., Folb, P.I., 2003. Project Coast: Apartheid's Chemical and Biological Warfare Programme, United Nations.

Grynkiewicz, G., Poenie, M., Tsien, R.Y., 1985. A new generation of Ca2+ indicators with greatly improved fluorescence properties. J Biol.Chem. 260, 3440-3450.

Hoffmann, U., Papendorf, T., 2006. Organophosphate poisonings with parathion and dimethoate. Intensive Care Med 32, 464-468.

Ivens, I.A., Schmuck, G., Machemer, L., 1998. Learning and memory of rats after long-term administration of low doses of parathion. Toxicol Sci 46, 101-111.

Johnson, F.O., Chambers, J.E., Nail, C.A., Givaruangsawat, S., Carr, R.L., 2009. Developmental chlorpyrifos and methyl parathion exposure alters radial-arm maze performance in juvenile and adult rats. Toxicol Sci 109, 132-142.

Kadriu, B., Guidotti, A., Costa, E., Auta, J., 2009. Imidazenil, a non-sedating anticonvulsant benzodiazepine, is more potent than diazepam in protecting against DFP-induced seizures and neuronal damage. Toxicology 256, 164-174.

Li, Y., Lein, P.J., Liu, C., Bruun, D.A., Tewolde, T., Ford, G., Ford, B.D., 2011. Spatiotemporal pattern of neuronal injury induced by DFP in rats: a model for delayed neuronal cell death following acute OP intoxication. Toxicol Appl Pharmacol 253, 261-269.

McDonough, J.H., Jr., Dochterman, L.W., Smith, C.D., Shih, T.M., 1995. Protection against nerve agent-induced neuropathology, but not cardiac pathology, is associated with the anticonvulsant action of drug treatment. Neurotoxicology 16, 123-132. 
McDonough, J.H., Jr., Shih, T.M., 1993. Pharmacological modulation of soman-induced seizures. Neurosci Biobehav Rev 17, 203-215.

Moorcraft, P., McLaughlin, P., 2008. The Rhodesian War: A Military History., Yorkshire: Pen \& Sword.

Nagarkatti, N., Deshpande, L.S., Carter, D.S., DeLorenzo, R.J., 2010. Dantrolene inhibits the calcium plateau and prevents the development of spontaneous recurrent epileptiform discharges following in vitro status epilepticus. Eur J Neurosci 32, 80-88.

Nagarkatti, N., Deshpande, L.S., DeLorenzo, R.J., 2008. Levetiracetam inhibits both ryanodine and IP3 receptor activated calcium induced calcium release in hippocampal neurons in culture. Neurosci Lett 436, 289-293.

Petrikovics, I., Papahadjopoulos, D., Hong, K., Cheng, T.C., Baskin, S.I., Jiang, J., Jaszberenyi, J.C., Logue, B.A., Szilasi, M., McGuinn, W.D., Way, J.L., 2004. Comparing therapeutic and prophylactic protection against the lethal effect of paraoxon. Toxicol Sci 77, 258-262.

Racine, R.J., 1972. Modification of seizure activity by electrical stimulation. II. Motor seizure. Electroencephalogr Clin Neurophysiol 32, 281-294.

Rauh, V.A., Perera, F.P., Horton, M.K., Whyatt, R.M., Bansal, R., Hao, X., Liu, J., Barr, D.B., Slotkin, T.A., Peterson, B.S., 2012. Brain anomalies in children exposed prenatally to a common organophosphate pesticide. Proc Natl Acad Sci U S A 109, 7871-7876.

Raza, M., Blair, R.E., Sombati, S., Carter, D.S., Deshpande, L.S., DeLorenzo, R.J., 2004. Evidence that injury-induced changes in hippocampal neuronal calcium dynamics during epileptogenesis cause acquired epilepsy. Proc Natl Acad Sci U S A 101, 17522-17527.

Raza, M., Deshpande, L.S., Blair, R.E., Carter, D.S., Sombati, S., DeLorenzo, R.J., 2007. Aging is associated with elevated intracellular calcium levels and altered calcium homeostatic mechanisms in hippocampal neurons. Neurosci Lett 418, 77-81.

Rice, A.C., Floyd, C.L., Lyeth, B.G., Hamm, R.J., DeLorenzo, R.J., 1998. Status epilepticus causes long-term NMDA receptor-dependent behavioral changes and cognitive deficits. Epilepsia 39, 1148-1157.

Ruckart, P.Z., Kakolewski, K., Bove, F.J., Kaye, W.E., 2004. Long-term neurobehavioral health effects of methyl parathion exposure in children in Mississippi and Ohio. Environ Health Perspect 112, 46-51.

Shih, T.M., Rowland, T.C., McDonough, J.H., 2007. Anticonvulsants for nerve agent-induced seizures: The influence of the therapeutic dose of atropine. J Pharmacol Exp Ther 320, 154-161.

Steenland, K., Jenkins, B., Ames, R.G., O'Malley, M., Chrislip, D., Russo, J., 1994. Chronic neurological sequelae to organophosphate pesticide poisoning. Am J Public Health 84, 731-736. 
Sun, D.A., Deshpande, L.S., Sombati, S., Baranova, A., Wilson, M.S., Hamm, R.J., DeLorenzo, R.J., 2008. Traumatic brain injury causes a long-lasting calcium (Ca2+)-plateau of elevated intracellular $\mathrm{Ca}$ levels and altered $\mathrm{Ca} 2+$ homeostatic mechanisms in hippocampal neurons surviving brain injury. Eur J Neurosci 27, 1659-1672.

Terry, A.V., Jr., Beck, W.D., Warner, S., Vandenhuerk, L., Callahan, P.M., 2012. Chronic impairments in spatial learning and memory in rats previously exposed to chlorpyrfos or diisopropylfluorophosphate. Neurotoxicol Teratol 34, 1-8.

Todorovic, M.S., Cowan, M.L., Balint, C.A., Sun, C., Kapur, J., 2012. Characterization of status epilepticus induced by two organophosphates in rats. Epilepsy Res 101, 268-276.

Wesseling, C., Keifer, M., Ahlbom, A., McConnell, R., Moon, J.D., Rosenstock, L., Hogstedt, C., 2002. Long-term neurobehavioral effects of mild poisonings with organophosphate and n-methyl carbamate pesticides among banana workers. Int J Occup Environ Health 8, 27-34.

Wright, L.K., Liu, J., Nallapaneni, A., Pope, C.N., 2009. Behavioral sequelae following acute diisopropylfluorophosphate intoxication in rats: Comparative effects of atropine and cannabinomimetics. Neurotoxicol Teratol 32, 329-335.

Zaja-Milatovic, S., Gupta, R.C., Aschner, M., Milatovic, D., 2009. Protection of DFP-induced oxidative damage and neurodegeneration by antioxidants and NMDA receptor antagonist. Toxicol Appl Pharmacol 240, 124-131. 


\section{Figure Legends}

Figure 1. A representative continuous 24-h EEG recording from a rat before, during and after POX induced SE. Baseline EEG activity is noted before POX exposure. This leads to intense SE minutes after POX administration (4 mg/kg, s.c.). (a) Expanded Depicts an expanded EEG segment of SE characterized by high frequency spiking. SE is robust, intense and doesn't wax and wane for the entire 1-h. SE is stopped at 1-h following administration of diazepam (DZP). (b) Expanded EEG segment after $1^{\text {st }}$ DZP ( $5 \mathrm{mg} / \mathrm{kg}$, i.p.) depicting rapid termination of SE. Two additional DZP and 2-PAM injections are administered at 3 and 5-h after SE onset. SE remained suppressed and seizures did not reoccur for the 24-h period following POX toxicity symptoms. Traces are representative of $n=6$ animals.

Figure 2. EEG progression of POX induced SE. (A) Baseline activity prior to POX injection. (B) Low-voltage fast activity appears within 2-3 min of POX administration. (C) High-voltage slow activity appears within the next minute that progresses to (D) high frequency and high-voltage spiking and (E and F) sustained continuous seizure activity. EEG activity at 15-min following POX administration (F) demonstrates electrographic SE with fully developed continuous seizures. Spike frequency during SE was sustained at greater than 7-10 Hz. SE was induced by POX within 5-7 min following injections. EEG activity correlated with behavioral observations.

Figure 3. Effect of POX induced SE on $\left[\mathrm{Ca}^{2+}\right]_{\mathrm{i}}$. (A) Pseudocolor ratiometric images of representative control and POX treated isolated neurons. Control neurons had bluish color that corresponds to lower Fura-2 ratio while POX-SE neurons had orange-red color that corresponds to higher Fura-2 ratio. (B) Elevated $\left[\mathrm{Ca}^{2+}\right]_{\mathrm{i}}$ in $\mathrm{CA} 1$ hippocampal neurons acutely isolated from 
animals that had experienced 1-h of POX induced SE compared to neurons from control animals. $\left({ }^{*} \mathrm{p}<0.001, t\right.$-test, $\mathrm{n}=6$ and 5 animals respectively). Data are represented as mean $\pm \mathrm{SEM}$.

Figure 4. Distribution of $\left[\mathrm{Ca}^{2+}\right]_{\mathrm{i}}$ for control and POX-SE hippocampal neurons. Control neurons demonstrated a normal distribution for $\left[\mathrm{Ca}^{2+}\right]_{\mathrm{i}}$ with approximately $95 \%$ of neurons exhibiting $\left[\mathrm{Ca}^{2+}\right]_{\mathrm{i}}$ less than $500 \mathrm{nM}$ and only $5 \%$ neurons exhibiting very high $\left[\mathrm{Ca}^{2+}\right]_{\mathrm{i}}$. In contrast, POX-SE neurons demonstrated a rightward shift towards higher $\left[\mathrm{Ca}^{2+}\right]_{i}$ with approximately $60 \%$ neurons exhibiting $\left[\mathrm{Ca}^{2+}\right]_{\mathrm{i}}$ greater than $500 \mathrm{nM}(\mathrm{n}=136$ neurons).

Figure 5. Development of $\mathrm{Ca}^{2+}$ plateau following POX induced SE. CA1 hippocampal $\left[\mathrm{Ca}^{2+}\right]_{i}$ from control (white bar) and POX rats were isolated immediately after (1-h) and 1, 7 and 30 days after SE (black bars). $\left[\mathrm{Ca}^{2+}\right]_{\mathrm{i}}$ in control animals at each time point were not significantly different from the control values shown and thus were omitted from the graph for clarity. $\left[\mathrm{Ca}^{2+}\right]_{\mathrm{i}}$ in neurons isolated from POX-SE rats was significantly higher than control values $(* \mathrm{p}<0.05$, oneway ANOVA, post hoc Tukey test, $n=6$ rats at each time). Data represented as mean \pm SEM.

Figure 6. Mechanism of $\mathrm{Ca}^{2+}$ plateau following POX SE. CA1 hippocampal $\left[\mathrm{Ca}^{2+}\right]_{\mathrm{i}}$ from control (white bar) and POX rats were isolated 24-h after SE (black bars). Dantrolene (Dant, $50 \mu \mathrm{M}$, bath application) caused a significant decrease in elevated post $\mathrm{SE} \mathrm{Ca}^{2+}$ levels. In separate experiments, rats were injected with either levetiracetam (LEV, $50 \mathrm{mg} / \mathrm{kg}$, i.p.) or carisbamate (CRB, $90 \mathrm{mg} / \mathrm{kg}$, i.p.) at 1, 6 and 18 -h post SE onset. CA1 hippocampal neurons were isolated 30-mins post the last drug injection. $\left[\mathrm{Ca}^{2+}\right]_{\mathrm{i}}$ in neurons isolated from POX-SE rats treated with either LEV or CRB were significantly lower than comparable POX SE rats (no drugs) values at the respective time point. $\left({ }^{*} \mathrm{p}<0.05\right.$, compared to POX, one-way ANOVA, post-hoc Tukey test, $\mathrm{n}=5$ animals for each treatment). Data represented as mean \pm SEM. 
Figure 7. POX SE induced neuronal injury. A. Representative photomicrographs of Fluoro-Jade $\mathrm{C}$ (FJC) staining in the (a) dentate gyrus-hilus region, (b) thalamus, (c) parietal cortex and (d) temporal/ peri-rhinal cortex of a control rat (left panel, c) and a POX rat 2 days after POX SE (4 $\mathrm{mg} / \mathrm{kg}$, s.c.) Scale bars, $200 \mu \mathrm{m}$. B. Quantitative analyses of FJC labeling. FJC positive cells indicative of neuronal injury were observed in hilus, thalamus and cortex of POX rats 48-h after SE termination. Control rats did not exhibit any FJC labeling. ( ${ }^{*} \mathrm{p}<0.05$ compared to control, $\mathrm{t}-$ test, $n=4-6$ rats). 
Table 1: Dose dependent effects of POX on SE and mortality

\begin{tabular}{|c|c|c|}
\hline $\begin{array}{c}\text { Dose of POX } \\
\text { (mg/kg, s.c., } \\
\text { n= 5-8) }\end{array}$ & \% SE & \% Mortality \\
\hline 0.1 & $7 \pm 2$ & 0 \\
\hline 0.5 & $42 \pm 7$ & $26 \pm 5$ \\
\hline 0.8 & $71 \pm 6$ & $50 \pm 6$ \\
\hline 1 & $81 \pm 4$ & $88 \pm 4$ \\
\hline 2 & $90 \pm 2$ & 100 \\
\hline 4 & 100 & 100 \\
\hline 8 & 100 & 100 \\
\hline
\end{tabular}


Table 2: Characteristics of POX induced SE

\begin{tabular}{|c|c|c|c|}
\hline $\begin{array}{c}\text { POX dose } \\
(\mathbf{m g} / \mathbf{k g}, \mathbf{s . c .}, \mathbf{n = 8})\end{array}$ & $\begin{array}{c}\text { SE onset time } \\
\text { (min.) }\end{array}$ & $\begin{array}{c}\text { Racine Score } \\
\text { (scale: 0-5) }\end{array}$ & $\begin{array}{c}\text { Time of death } \\
\text { (min.) }\end{array}$ \\
\hline 0.1 & $37 \pm 3$ & 2 & - \\
\hline 0.5 & $19 \pm 1$ & 2 & $32 \pm 3$ \\
\hline 0.8 & $11 \pm 1$ & 4 & $26 \pm 4$ \\
\hline 1 & $7 \pm 0.5$ & 5 & $12 \pm 1$ \\
\hline 2 & $5 \pm 0.5$ & 5 & $7 \pm 0.5$ \\
\hline 4 & $3 \pm 0.2$ & 5 & $5 \pm 0.2$ \\
\hline 8 & $2 \pm 0.4$ & 5 & $3 \pm 0.2$ \\
\hline
\end{tabular}


Table 3: Role of three-drug regimen in promoting survival following lethal POX intoxication

\begin{tabular}{|l|l|l|l|l|}
\hline Time post SE & \multicolumn{4}{|l|}{ Percent survival following POX SE in the presence of } \\
\hline & No drug & Atropine & $\begin{array}{l}\text { Atropine + } \\
\text { 2-PAM }\end{array}$ & $\begin{array}{l}\text { Atropine + 2-PAM } \\
+ \text { diazepam }\end{array}$ \\
\hline 1-h & 0 & $71 \pm 4$ & $83 \pm 6$ & $88 \pm 4$ \\
\hline $24-\mathrm{h}$ & - & $41 \pm 4$ & $50 \pm 6$ & $83 \pm 6$ \\
\hline $48-\mathrm{h}$ & - & $33 \pm 6$ & $41 \pm 4$ & $79 \pm 8$ \\
\hline $72-\mathrm{h}$ & - & $12 \pm 4$ & $21 \pm 4$ & $79 \pm 8$ \\
\hline
\end{tabular}

$\mathrm{n}=8$ for no drug condition and $\mathrm{n}=24$ for each separate drug combination 

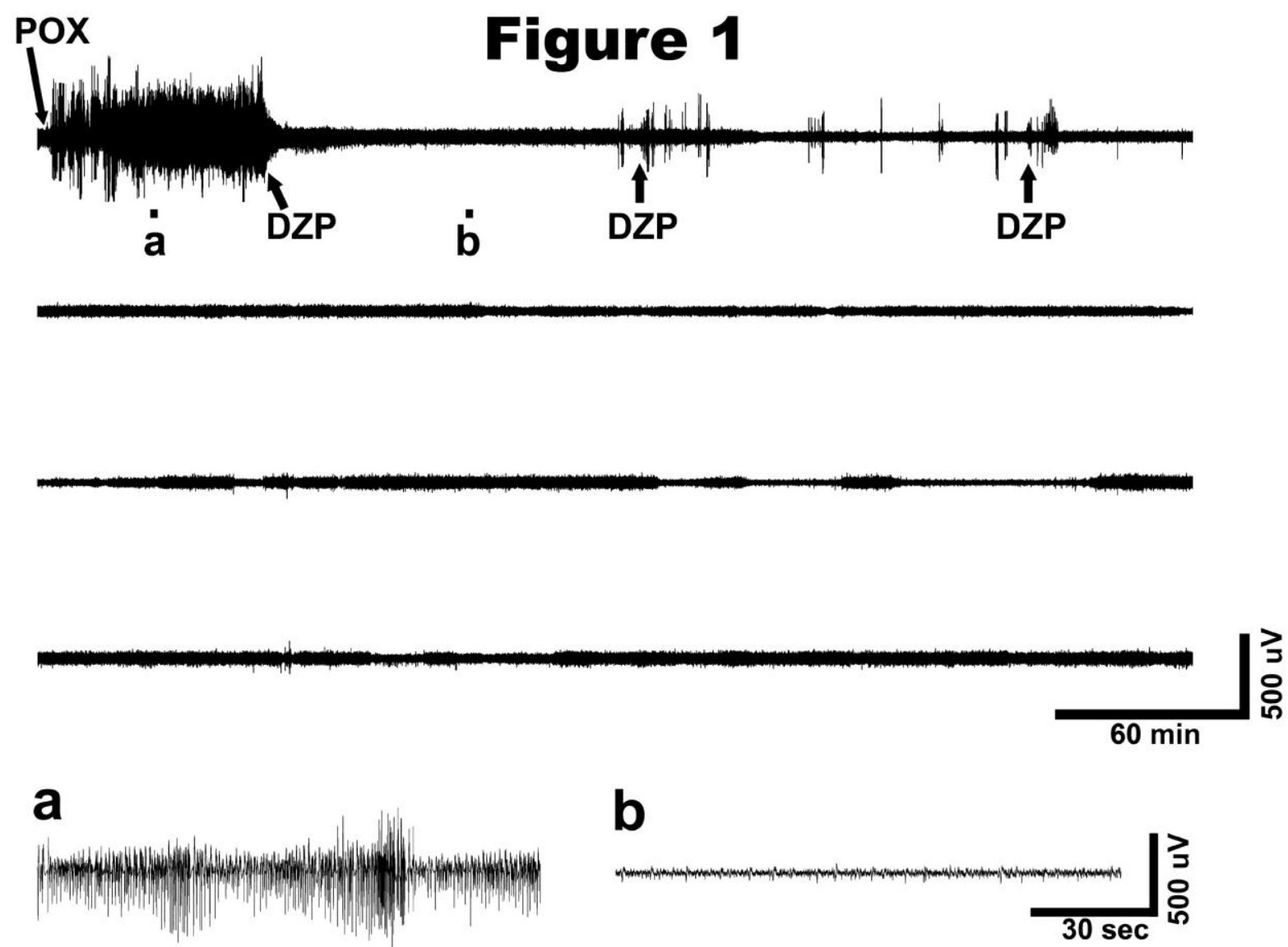

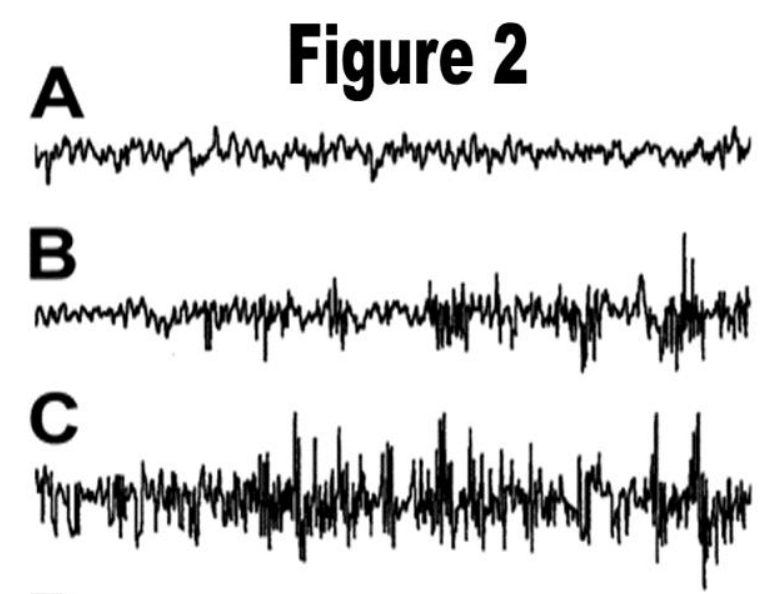

D
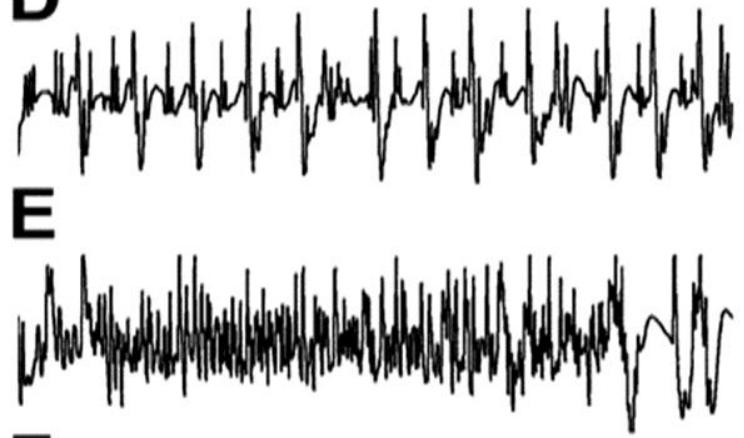

$F$

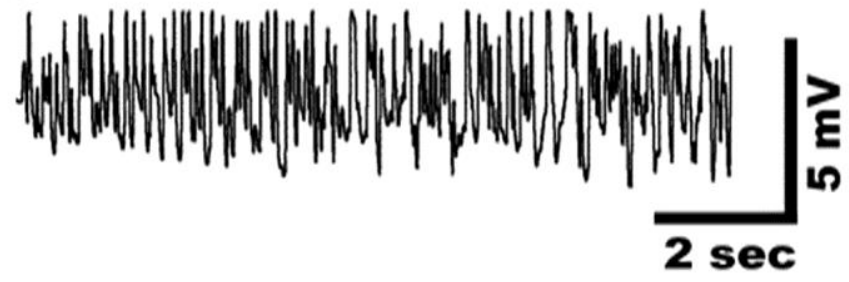




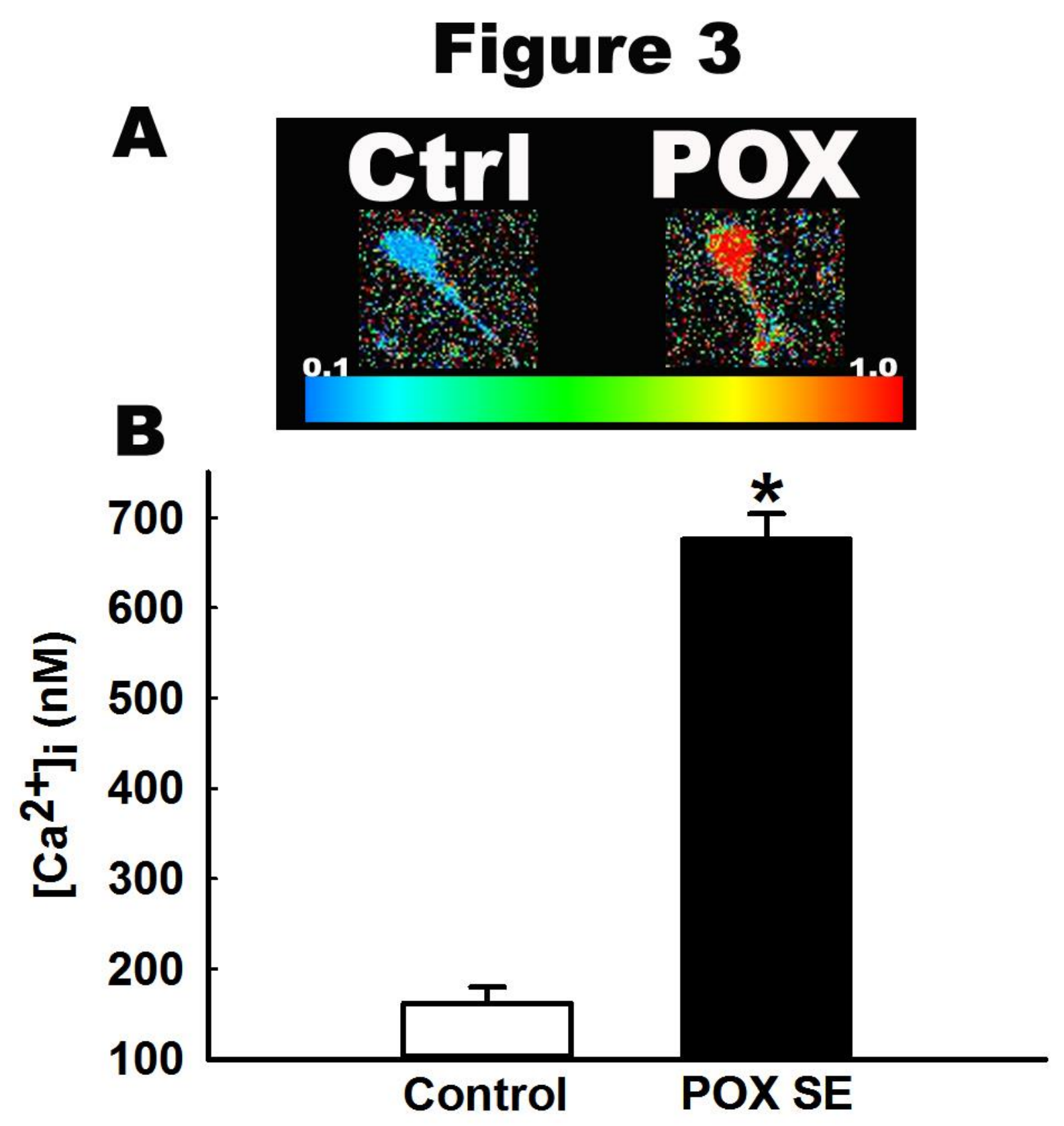




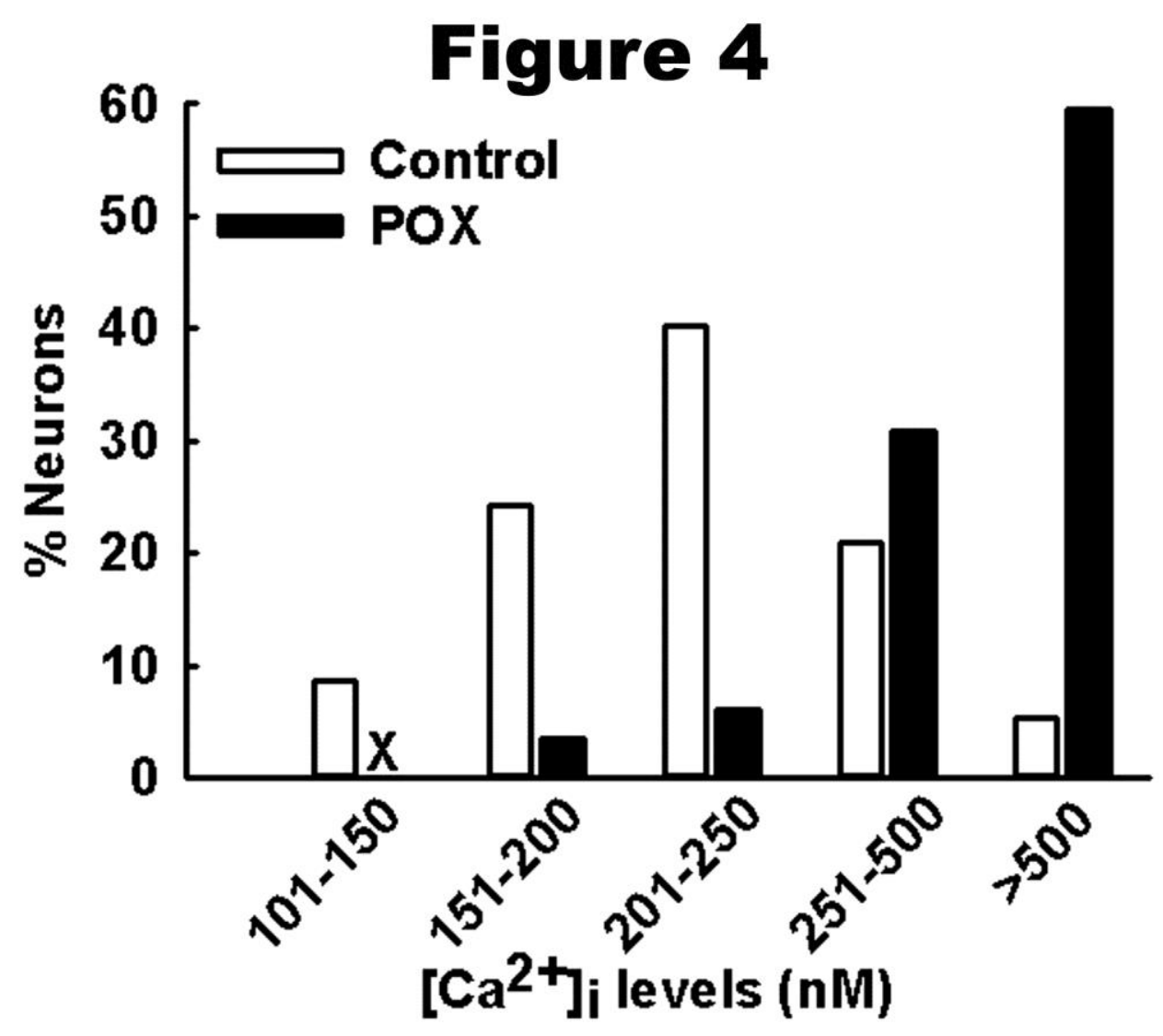




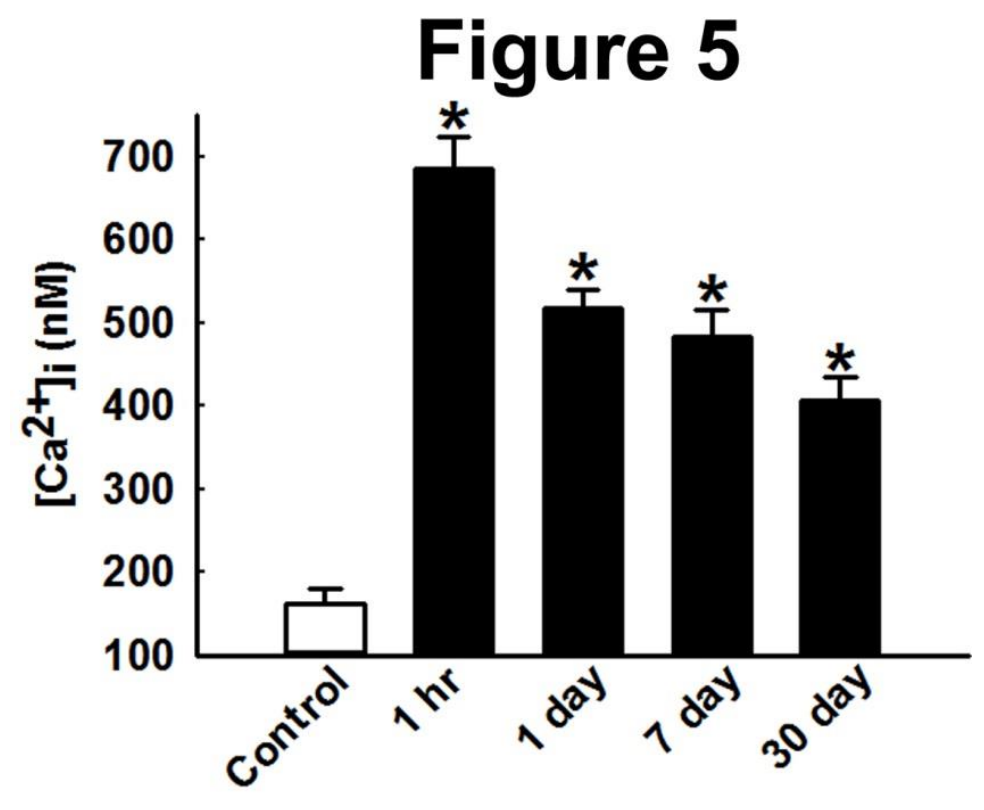




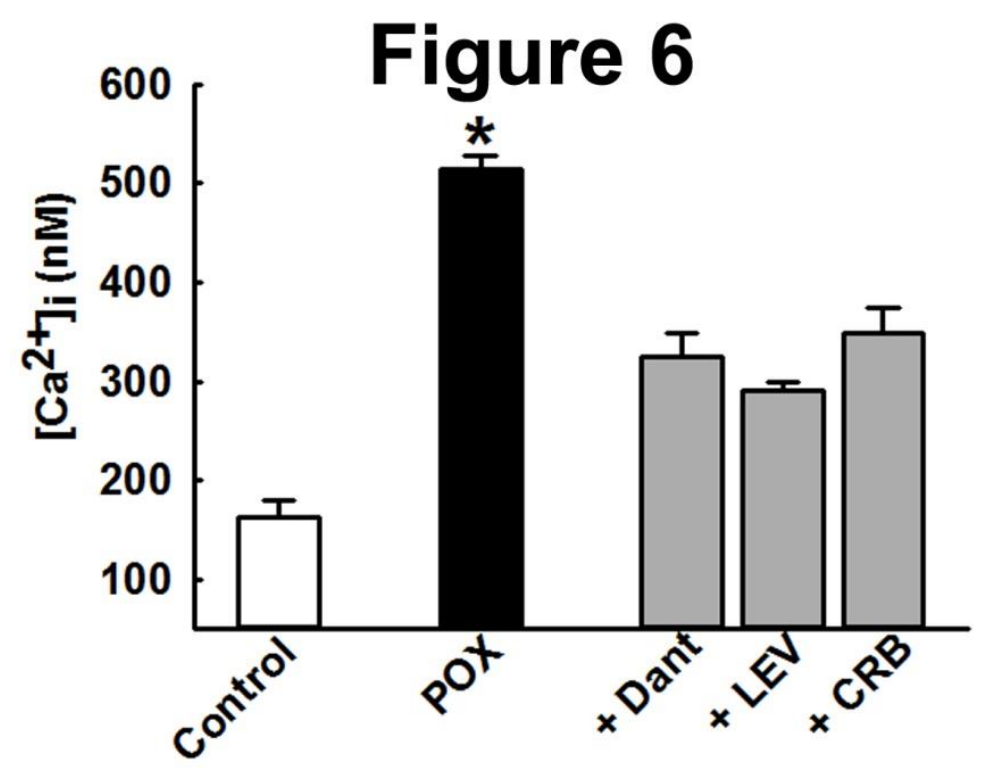




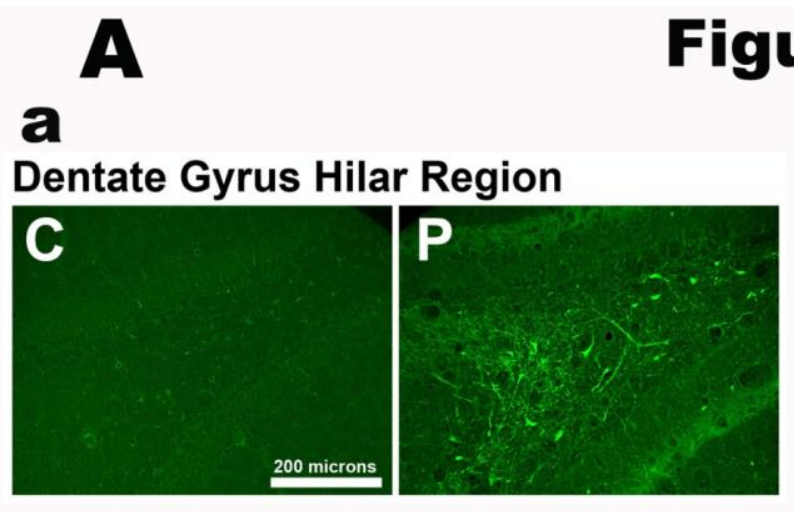

Figure 7

b

Thalamus

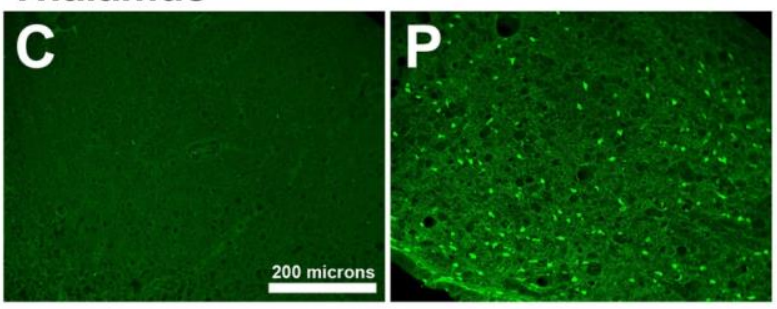

C

d

Parietal Cortex

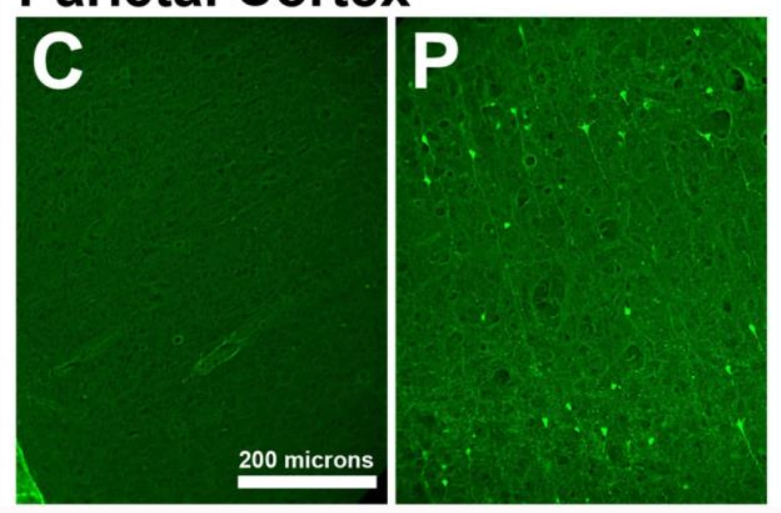

\section{Temporal/Perirhinal Cortex}

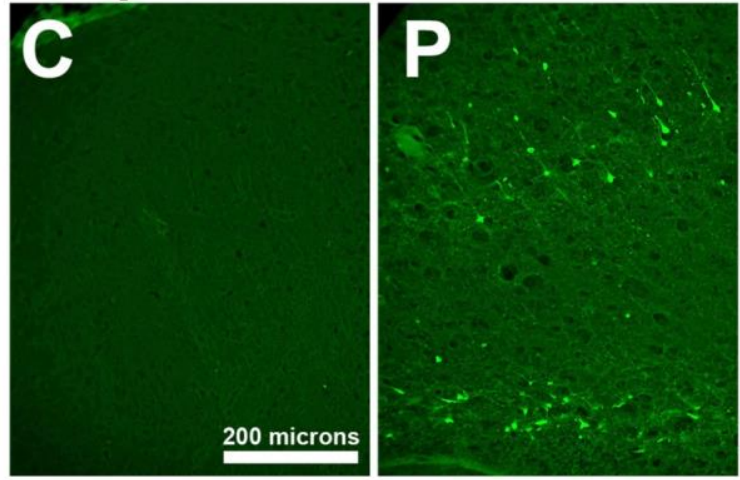

B

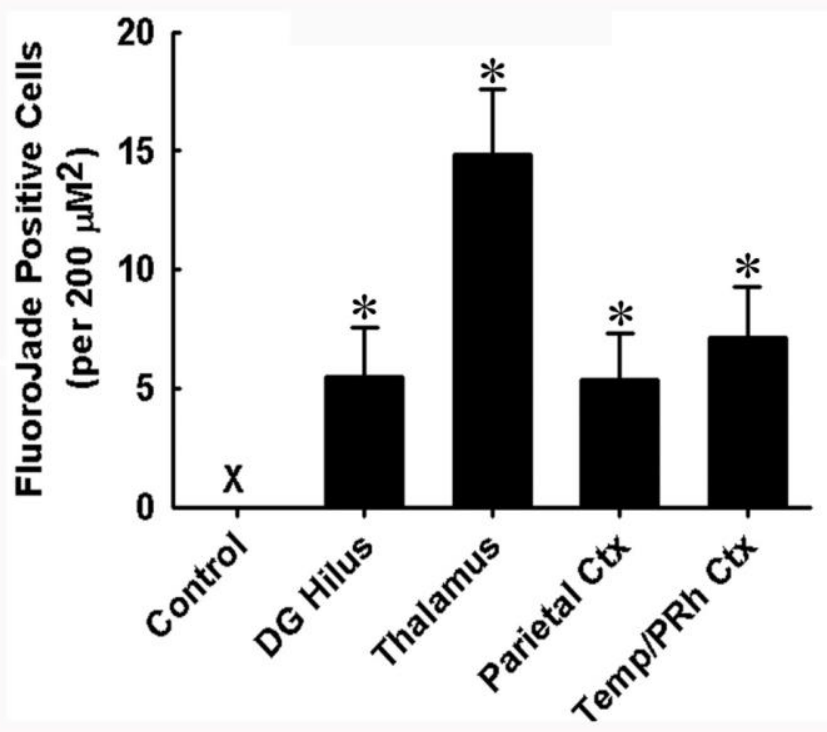

